\title{
The Role of the Sharing Economy and Artificial Intelligence in Health Care: Opportunities and Challenges
}

Huailiang $\mathrm{Wu}^{1,2^{*}}$, MBBS; Nga-Kwo Chan ${ }^{1,2^{*}}$, MBBS; Casper J P Zhang ${ }^{3}$, MPH, PhD; Wai-Kit Ming ${ }^{1,2,4}$, MD, PhD, MPH, MMSc

\author{
${ }^{1}$ International School, Jinan University, Guangzhou, China \\ ${ }^{2}$ School of Medicine, Jinan University, Guangzhou, China \\ ${ }^{3}$ School of Public Health, The University of Hong Kong, Hong Kong, China \\ ${ }^{4}$ HSBC Business School, Peking University, Shenzhen, China \\ *these authors contributed equally
}

\section{Corresponding Author:}

Wai-Kit Ming, MD, PhD, MPH, MMSc

School of Medicine

Jinan University

601 West Huangpu Avenue

Guangzhou

China

Phone: 8614715485116

Email: wkming@connect.hku.hk

\begin{abstract}
Health care systems worldwide have been influenced by the globally growing trend toward a sharing economy and will likely advance with these trends in the near future. Therefore, based on peer-to-peer relationships between individuals, sharing health care works by renting medical staff, facilities, and other medical resources. Medical data innovation, integration, analysis, and sharing have the potential to dramatically change the current pattern of the health care system and to provide precise and predictive medical assessment for individuals in the future. In addition, artificial intelligence could be useful in the fields of both clinical medicine and medical research and help to minimize the scarcity of human resources and broaden the role of humans in health care.
\end{abstract}

(J Med Internet Res 2019;21(10):e13469) doi: $\underline{10.2196 / 13469}$

\section{KEYWORDS}

health care; health care system; sharing economy; artificial intelligence

The scarcity of health care resources is a long-standing, persistent global issue that is increasing with the worldwide aging population [1]. Possible approaches toward alleviating this scarcity include applying a sharing economy model to the health care industry [2]. The concept of sharing has been incorporated into a range of commercial activities related to daily life, such as retail and transportation. The health care system has also been influenced by the globally growing trend toward a sharing economy [3] and will likely advance with these trends in the near future. Such foreseeable trends continually accompany the integration of innovative technology in the emerging big-data era, including artificial intelligence (AI). Decision making on global issues requires new technologies based on AI techniques [4]. AI techniques are also needed in clinical prediction, diagnostics, and therapeutics and can be implemented by "learning" from appropriate data (eg, in image-related specialties) [5].

China is currently experiencing rapid economic development and growing health care needs. Given these circumstances, the Chinese health care system seems ideally suited to serve as a testing ground to assess the practicality of advancing health care systems using AI.

Residents of most regions in mainland China are provided with universal health insurance, which means that patients usually only pay a small portion of the treatment fee [6]. In most circumstances, routine treatments involve visiting neighborhood clinics supported by the public sector and then hospitals, if needed. Although reform and development of the primary health care system are proceeding in China, some challenges remain including fragmented health care information and a paucity of 
digital data [7]. In Hong Kong, the health care system has a dual-track structure encompassing the public and private sectors [8]. Public health care, operationalized by public hospitals, is the cornerstone of the health care system in Hong Kong, accounting for approximately $90 \%$ of health services and $29 \%$ of outpatient services. Hong Kong public health care also provides a comprehensive range of quality services at very low costs (eg, US $\$ 13 /$ bed/day), which is made possible by a high subsidy rate [7]. In Hong Kong, private clinics complement the public sector. The American system differs from those in mainland China and Hong Kong and involves a hybrid system that includes the federal government, local governments, and private funds (households and private businesses). It is estimated that American citizens have greater health care costs than other developed countries [9]; this is likely because most US health care services are delivered privately, even if they are publicly financed. Selected characteristics (physicians, hospital beds, and mean costs) of the health care systems of mainland China, Hong Kong, and the United States are compared in Table 1. The World Health Organization has specified a minimum of 2.5 health care professionals (physicians, nurses, and midwives) per 1000 people for essential primary care coverage; among the three systems detailed here, only the United States has met this criterion.

Table 1. Characteristics of the selected health care systems (2016).

\begin{tabular}{llll}
\hline Characteristic & Mainland China & Hong Kong Special Administrative Region & United States \\
\hline Physicians per 1000 people & $2.31^{\mathrm{a}}$ & $1.90^{\mathrm{b}}$ & $2.55^{\mathrm{c}}$ \\
Hospital beds per 1000 people & $5.37^{\mathrm{a}}$ & $5.32^{\mathrm{b}}$ & $2.5^{\mathrm{d}}$ \\
Mean cost per patient (US \$) & $1801.74^{\mathrm{a}}$ & $2208.37^{\mathrm{b}}$ & $9990^{\mathrm{c}}$ \\
\hline
\end{tabular}

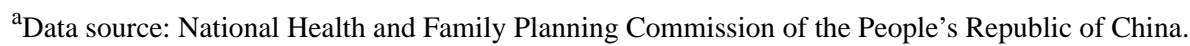

${ }^{b}$ Data source: Department of Health, Hong Kong Special Administrative Region.

${ }^{\mathrm{c}}$ Data source: US Department of Health and Human Services.

${ }^{\mathrm{d}}$ Data source: 2014 World Health Organization report.

In a classical health care system, primary care is mainly provided by family physicians. Family physicians are expected to offer appropriate advice and diagnoses at the early stages of illness. This type of health care requires familiarity with patients' conditions (eg, drug allergies or idiopathic issues) and therefore represents a patient-centered approach characterized by preventive and coordinated actions [10]. However, the corresponding costs associated with this comprehensive care tend to be high and can vary across patients. In recent years, the concept of sharing health care has emerged. Sharing health care is based on a peer-to-peer relationship between individuals with similar economic/social roles and works by renting medical staff, facilities, and other medical resources. For example, doctors will practice in single hospitals, clinics, or private health care facilities as well as other locations in a more flexible fashion. This sharing health care system will be similar to other growing sharing businesses (eg, Airbnb, Mobike, and Uber), which are characterized by low entry requirements and high efficiency [2]. In this vision of the future, family physicians will engage in medical record sharing (with informed consent) and paramedic and facility sharing; therefore, with the same limited resources, a larger proportion of patients could receive primary medical care. With the application of principles of sharing economy in medicine, more patients look for medical information on the internet and make decisions based upon that information [11].

The term crowdfunding originally refers to the collective effort of consumers who offer funding to support and sustain a project [12]. Today, an interesting application of sharing economy in health care has emerged in mainland China (eg, among users of Wechat, Weibo, QQ, and other social networking). We consider the application of sharing economy in health care as a type of "charitable crowdfunding," which refers to crowdfunding projects that aim to help the poor, disabled, and other disadvantaged people to pay their health care budgets. As an example, since its foundation in 2015 until September 2018, one popular charitable crowdfunding project in mainland China- "fun in funding"- has already raised more than 55 billion RMB and helped 2.5 million families overcome fatal diseases such as leukemia and lung cancer. Many ordinary people donate just a few RMB, but with the spread of donation messages, more donations follow. As a result, such approaches are likely to raise the targeted money for poor and severely ill patients. Although there is no accurate or reliable statistical data of all funding used in this practice, we believe that this innovation of crowdfunding application has succeeded in helping many low-income families and people with genetic diseases to treat their illnesses. Furthermore, this can help fill the gap of the current health insurance system because all types of health insurance can only cover about $70 \%-80 \%$ of the expenditure if the expenditure does not exceed the reimbursement cap (Figure 1). 
Figure 1. A comparison of the Health Insurance Systems of mainland China, the United Kingdom, and the United States. Source for data on BMISUE, BMISUR, and NRCMS is Han and Meng [13]. BMISUE: Basic Medical Insurance System for Urban Employees; BMISUR: Basic Medical Insurance System for Residents; NRCMS: New Rural Cooperative Medical System; NHS: National Health Service; CHIP: Children's Health Insurance Program; ALS: amyotrophic lateral sclerosis; ESRD: end-stage renal disease.

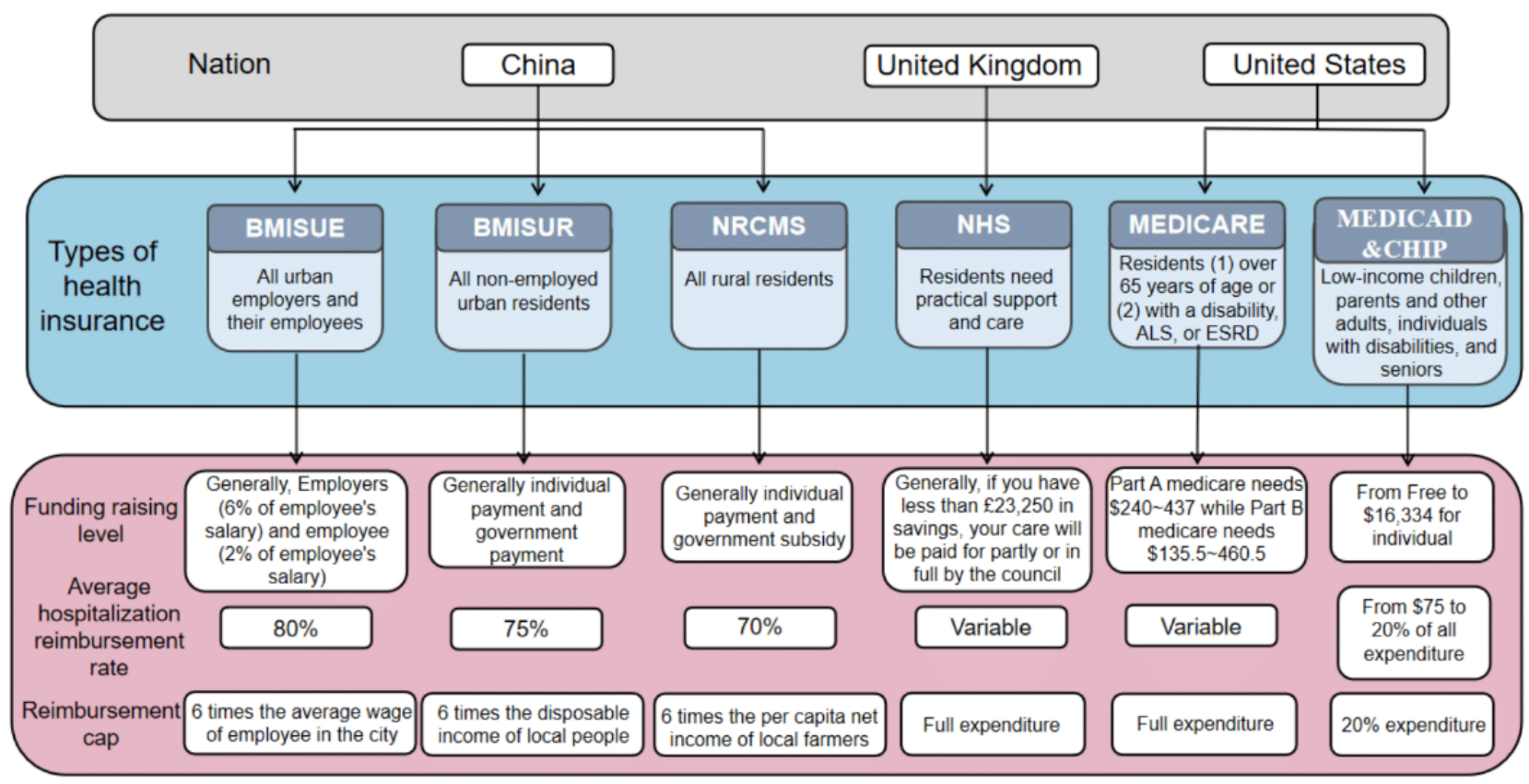

Medical data innovation, integration, analysis, and sharing have the potential to dramatically change the current pattern of the health care system worldwide and provide precise and predictive medical assessment for individuals in the future [14,15]. In addition, decision makers should provide a sufficient medical budget and lead the digitizing health care process through cooperation among the various health care organizations (hospitals, private medical constitutes, and charitable companies) to achieve development of health care systems.

The development of AI has been considerable over the past several decades, and it is conceivable that it could be applied to the medical field, particularly to data evaluation. In about 20 years, half of all work is expected to be out of date or no longer needed, and medical health care is not exempt from AI development [16]. AI could be useful in the fields of clinical medicine and medical research and help minimize the scarcity of human resources and broaden the role of human beings in health care. Given the popularity of personal smart devices, the idea of adopting AI for personal health care services is no longer out of reach and is increasingly viable.

AI technology will indeed help health care professionals provide more care for a larger number of patients, make better clinical decisions, and reduce unnecessary hospitalization and health care costs [17]. However, it is essential to assess the ethical issues in the application of AI technology in health care. Does AI involvement change the doctor-patient relationship and who is responsible for technology-assisted decisions when patients are harmed? Besides, without the clinical physician's involvement, how will patients be reassured and kept emotionally stable? All of these issues require further consideration if effective solutions are to be identified.

When working toward achieving these goals, governments and health care providers must obtain a deeper understanding of patients' preferences of AI in primary care and investigate the applicability of adopting a sharing health care business model.

\section{Conflicts of Interest}

None declared.

\section{References}

1. Yang Q, Dong H. Have health human resources become more equal between rural and urban areas after the new reform? Int J Health Policy Manag 2014 Dec 03;3(7):359-360 [FREE Full text] [doi: 10.15171/ijhpm.2014.129] [Medline: 25489591]

2. Miller BJ, Moore DW, Schmidt CW. Telemedicine and the sharing economy: the "Uber" for healthcare. Am J Manag Care 2016 Dec 01;22(12):e420-e422 [FREE Full text] [Medline: 27982670]

3. Demiris G. Consumer Health Informatics: Past, Present, and Future of a Rapidly Evolving Domain. Yearb Med Inform 2018 Mar 06;25(S 01):S42-S47. [doi: 10.15265/iys-2016-s005]

4. Fernandez-Luque L, Imran M. Humanitarian health computing using artificial intelligence and social media: A narrative literature review. Int J Med Inform 2018 Jun;114:136-142. [doi: 10.1016/j.ijmedinf.2018.01.015] [Medline: 29395987] 
5. Maddox TM, Rumsfeld JS, Payne PRO. Questions for Artificial Intelligence in Health Care. JAMA 2019 Jan 01;321(1):31-32. [doi: 10.1001/jama.2018.18932] [Medline: 30535130]

6. Kong X, Yang Y, Gao J, Guan J, Liu Y, Wang R, et al. Overview of the health care system in Hong Kong and its referential significance to mainland China. J Chin Med Assoc 2015 Oct;78(10):569-573 [FREE Full text] [doi: 10.1016/j.jcma.2015.02.006] [Medline: 26144022]

7. Li X, Lu J, Hu S, Cheng K, De Maeseneer J, Meng Q, et al. The primary health-care system in China. The Lancet 2017 Dec;390(10112):2584-2594. [doi: 10.1016/s0140-6736(17)33109-4]

8. Leung GM, Wong IO, Chan WS, Choi S, Lo SV, Health Care Financing Study Group. The ecology of health care in Hong Kong. Soc Sci Med 2005 Aug;61(3):577-590. [doi: 10.1016/j.socscimed.2004.12.029] [Medline: 15899317]

9. Hood VL, Weinberger SE. High value, cost-conscious care: an international imperative. Eur J Intern Med 2012 Sep;23(6):495-498. [doi: 10.1016/j.ejim.2012.03.006] [Medline: 22863424]

10. Committee on Hospital Care, American Academy of Pediatrics. Family-Centered Care and the Pediatrician's Role. PEDIATRICS 2003 Aug 29;112(3):691-696. [doi: 10.1542/peds.112.3.691]

11. Roper L, Jorm C. Preparing medical students for the e-patient: Is a theoretical grounding required? Medical Teacher 2017 Jul 25;39(10):1101-1101. [doi: 10.1080/0142159x.2017.1353072]

12. Chaney D. A principal-agent perspective on consumer co-production: Crowdfunding and the redefinition of consumer power. Technological Forecasting and Social Change 2019 Apr;141:74-84. [doi: 10.1016/j.techfore.2018.06.013]

13. Han J, Meng Y. Institutional differences and geographical disparity: the impact of medical insurance on the equity of health services utilization by the floating elderly population - evidence from China. Int J Equity Health 2019 Jun 14;18(1):91 [FREE Full text] [doi: 10.1186/s12939-019-0998-y] [Medline: $\underline{31200716]}$

14. Tang C, Plasek JM, Bates DW. Rethinking Data Sharing at the Dawn of a Health Data Economy: A Viewpoint. J Med Internet Res 2018 Nov 22;20(11):e11519 [FREE Full text] [doi: 10.2196/11519] [Medline: 30467103]

15. Moscatelli M, Manconi A, Pessina M, Fellegara G, Rampoldi S, Milanesi L, et al. An infrastructure for precision medicine through analysis of big data. BMC Bioinformatics 2018 Oct 15;19(Suppl 10):351 [FREE Full text] [doi: 10.1186/s12859-018-2300-5] [Medline: 30367571]

16. Frey CB, Osborne MA. The future of employment: How susceptible are jobs to computerisation? Technological Forecasting and Social Change 2017 Jan;114:254-280. [doi: 10.1016/j.techfore.2016.08.019]

17. Meskó B, Hetényi G, Győrffy Z. Will artificial intelligence solve the human resource crisis in healthcare? BMC Health Serv Res 2018 Jul 13;18(1):545 [FREE Full text] [doi: 10.1186/s12913-018-3359-4] [Medline: $\underline{30001717]}$

\title{
Abbreviations
}

AI: artificial intelligence

\author{
Edited by G Eysenbach; submitted 23.01.19; peer-reviewed by N Gertrudiz, F Saigí-Rubió; comments to author 27.04.19; revised \\ version received 04.07.19; accepted 19.08.19; published 15.10.19 \\ Please cite as: \\ Wu H, Chan NK, Zhang CJP, Ming WK \\ The Role of the Sharing Economy and Artificial Intelligence in Health Care: Opportunities and Challenges \\ J Med Internet Res 2019;21(10):e13469 \\ URL: https://www.jmir.org/2019/10/e13469 \\ doi: $10.2196 / 13469$ \\ PMID: 31617850
}

CHuailiang Wu, Nga-Kwo Chan, Casper J P Zhang, Wai-Kit Ming. Originally published in the Journal of Medical Internet Research (http://www.jmir.org), 15.10.2019. This is an open-access article distributed under the terms of the Creative Commons Attribution License (https://creativecommons.org/licenses/by/4.0/), which permits unrestricted use, distribution, and reproduction in any medium, provided the original work, first published in the Journal of Medical Internet Research, is properly cited. The complete bibliographic information, a link to the original publication on http://www.jmir.org/, as well as this copyright and license information must be included. 